\title{
Use of eQuest in the teaching of design and analysis of HVAC systems: lessons from Building Engineering courses
}

\author{
Radu Zmeureanu \\ Centre for Zero Energy Building Studies, Department of Building, Civil and Environmental \\ Engineering, Gina Cody School of Engineering and Computer Science, Concordia University, \\ Montreal, Quebec, Canada
}

\begin{abstract}
This paper presents the author's experience from courses that focused on the design and analysis of a complex HVAC system of a school building in compliance with National Energy Code of Canada for Buildings (NECB). The courses are designed to achieve the following teaching objectives: (i) exploration and application of NECB for the preliminary design, (ii) learning and usage of the eQuest energy analysis program, (iii) estimation of the whole building energy performance, along with the indices of performance of HVAC equipment, and (iv) learning from mistakes in the input data and HVAC system description. The students' results presented a large dispersion around the average values due to errors and misinterpretations. If only the annual whole building energy performance is analyzed, some input errors are not discovered. Other results directly extracted or calculated from the simulation results should be compared with codes requirements and indices from publications and consulting firms.
\end{abstract}

\section{Introduction}

The review of proceedings of the Building Simulation (BS) conference over the past 20 years revealed that only nine papers highlighted in the title the words of education, teaching, or students; three papers at BS 2017 (San Francisco), five papers at BS 2015 (Hyderabad), and one paper at BS 2011 (Sydney). In all 10 BS conferences, there were only two dedicated sessions: (i) Education at BS 2017, and (ii) Teaching modelling simulation at BS 2015.

Charles and Thomas (2009) developed an introductory course for a population of both undergraduate architecture and engineering students with the scope of achieving a balance between: (i) an insight gained through Building Performance Simulation (BPS), (ii) an insight gained through basic physics calculations, and (iii) an insight gained from measuring physical phenomena. Students were exposed to tools such as TRNSYS, CONTAM, Design Advisor, THERM, and WUFI-ORNL

Reinhart et al. (2011) applied a game-based learning approach for teaching BPS to architectural students. A class of 47 architecture students competed for the lowest Energy Use Intensity (EUI) of an office building in Boston. The students, divided into ten groups, selected between eleven building massings, eight orientations, building envelope configurations and electric lighting and control systems. The design baseline values were selected according to ASHRAE 90.1-2007. Other ten students with better knowledge carried out simulations using preconfigured DesignBuilder/EnergyPlus models. The EUIs of the final designs were $22 \%$ to $31 \%$ below the baseline model.

Beausoleil-Morrison and Hopfe (2015) concluded, from a detailed analysis of current situation, that the teaching of BPS should be done through a complete and continuous learning cycle, composed of four stages: (i) Application of BPS, (ii) Scrutinizing results, (iii) Diagnostic investigation, and (iv) Studying theory. They presented the experience from teaching a graduate-level course on BPS with 21 students. They were asked to predict the annual space heating and cooling loads, by using ESP-r and/or EnergyPlus programs, of one of the basic low-mass test cases defined in ASHRAE Standard 140 (ANSI/ASHRAE 2007). The students' results were compared with predictions from eight combinations of BPS tools and experienced users, presented in Standard 140. Through the analysis of results and diagnosis of errors, students were able to better understand the models and simulation methods.

Kumaraswamy and de Wilde (2015) discussed the education pathway on BPS followed by students at the undergraduate Architectural Technology program at Plymouth University (UK). Students registered in three modules in sequence: (i) ENBS117 that introduced students to theoretical aspects of building physics and HVAC systems; (ii) TECN201 that introduced students to a series of software such as IES, THERM, and SAP; and (iii) ATE202 where students used the software.

Rabenseifer (2015) used generic models (developed from models available in Physibel, TESS, and TRNSYS) controlled via external user-friendly interface using Excel Workbook. The generic models were designed for a particular type of building, building component or equipment. He concluded that the generic models represent a way to overcome the obstacles, which keep architects and designers from using BPS.

Strobe et al. (2015) presented the use of building information modelling (BIM) coupled with two models for the estimation of residential buildings heating demand; first model was based on the official calculation method in Flanders, and the second was a multi-zone model based on ISO 13790. The approach was used in a student exercise with 11 master students in architecture 
and engineering plus four exchange students. Every student used a different building type and topology. They used the passive house guidelines to estimate the energy use of baseline design, and then they explored the impact of several design alternatives. The authors concluded that students became aware about the impact of design choices.

Hopfe et al. (2017) presented the findings of a survey conducted at different architecture schools at universities in Australia, India, the US and the UK about teaching BPS.

Zweifel, G. (2017) presented the teaching of building simulation to students in a bachelor program, by using one core module (Modelling and Simulation 1), plus other elective modules. The focus of the core module is on the strength of building simulation as a means of integrated design. The module is composed of three parts: (i) the development of a mathematical-physical model of a problem; (ii) the development of a simple two-zone model, using IDA Indoor Climate and Energy (an equation based thermal simulation program); a sensitivity study and optimization were also included; and (iii) the introduction to computational fluid dynamics, or lighting and daylighting simulation. The scope of optimization exercise, carried out on a five-zone building model, was to minimize the overall operation primary energy use, while keeping the comfort conditions in an acceptable range.

The International Journal of Building Performance Simulation published a few papers related to this topic. For instance, Schmid (2008) explored the benefits of teaching building simulation to architectural students, knowing that most of them will not become simulation experts. The author's thesis was that building simulation has pedagogic relevance for architectural students, as they will be able to apply physical principles in the design process, and will become aware about the consequences of the design choices. The paper presented the results of case studies carried out between 2005 and 2008. He thought that students would acquire a comprehensive view of their decisions by using a professional simulation tool, rather than using simplified tools such as spreadsheets for estimating the building cooling loads.

Reinhart et al. (2012) expanded on an earlier paper about the use of game-based learning approach.

Beausoleil-Morrison's thesis (2018) was that a solid understanding of the fundamentals of BPS is critical for the good representation of physical processes in buildings and HVAC systems. He listed a few approaches used for teaching BPS. He expanded on the Experiential Learning Theory, applied in a previous paper by BeausoleilMorrison and Hopfe (2015), by including the BPS learning spiral, where the completion of a cycle of simulation of one topic should lead into the subsequent topic. He used this approach for a series of distinct heat or mass transfer processes. In the final step of integration of learnings, students predicted the thermal performance of a research house located on the Carleton University campus. Students compared their predictions with measurements, followed by the simulation autopsy to diagnose and understand causes of disagreement.

Bernier et al. (2016) presented, at the IBPSA-Canada conference, the structure of a graduate level course on building energy modeling and simulation with the scope of teaching fundamentals (governing equations, assumptions, and solution methods). The course was composed of 11 modules covered over 40 hours of lectures. Students solved manually the governing equations, for some applications, before using TRNSYS. In the building heat transfer module, students were exposed to three estimation methods: steady state, lumped-capacitance, and heat balance. In the module of HVAC equipment modeling, students were exposed to first principles models (e.g., heat transfer in a pipe subjected to a constant heat transfer rate), grey-box models (e.g., a heat pump model), and black box models (e.g., DOE-2 model for chillers). Other modules covered climatic data, lighting and daylighting, fenestration, occupants, calibration, infiltration/ventilation, thermal storage, and optimization. Students were exposed to programs such as TRNSYS, EES, WINDOW, ExcalibBEM, and SIMEB (interface to DOE-2.2), CONTAM, GenOpt, and BeOpt.

\section{Description of courses}

The undergraduate Building Engineering program at Concordia University in Montreal, Canada received continuous accreditation since 1982 from the Canadian Engineering Accreditation Board. For more than 30 years, it was the only Building Engineering program offered by Canadian universities. Recently, the program started at Université de Sherbrooke (Quebec) and Waterloo University (Ontario). Table 1 presents examples of core and elective courses. The department offers also graduate programs at the Master's and Ph.D. levels.

Table 1: Example of undergraduate courses.

\begin{tabular}{|c|c|}
\hline \multicolumn{2}{|c|}{ Building Engineering Core } \\
\hline BLDG 365 & Building Science \\
\hline BLDG 366 & Acoustics and Lighting \\
\hline BLDG 371 & Building Service Systems \\
\hline BLDG 463 & Building Envelope Design \\
\hline BLDG 471 & HVAC System Design \\
\hline BLDG 476 & Thermal Analysis of Buildings \\
\hline BLDG 490 & Capstone Building Engineering Design \\
& Project \\
\hline Option A - Building Energy and Environment \\
\hline BLDG 465 & Fire and Smoke Control in Buildings \\
\hline BLDG 472 & Building Energy Conservation Technologies \\
\hline BLDG 475 & Indoor Air Quality \\
\hline BLDG 477 & Control Systems in Buildings \\
\hline BLDG 479 & Commission of HVAC systems in buildings \\
\hline BLDG 483 & Integrated Solar Systems: Design and \\
& \begin{tabular}{c} 
Operation \\
\hline BLDG 484
\end{tabular} \\
\hline
\end{tabular}


The course outline of BLDG 472 and BLDG 6781 (a graduate course) has six chapters as follows:

Chapter 1 - Introduction. Life cycle cost and energy use of buildings. Net Zero Energy Buildings. Net Zero Carbon Buildings.

Chapter 2 - Energy estimating and modeling methods. Estimation of the annual energy consumption, demand and cost of new buildings. Comparison of design alternatives. Introduction to eQuest energy analysis program.

Chapter 3 - Building energy-related standards. National Energy Code of Canada for Buildings (NECB, 2015); Regulation respecting energy conservation in new buildings, E-1.1, r.1, Quebec; ASHRAE 90.1.

Chapter 4 - Estimation of embodied energy in building materials and equipment. Estimation of greenhouse gas emissions due to the building operation and construction. Introduction to Athena Impact Estimator software.

Chapter 5 - HVAC systems with high performance. Case studies.

Chapter 6 - Introduction to building commissioning, retro-commissioning and ongoing commissioning of existing buildings. Energy signature and weather normalization techniques.

For increasing the students' experiential learning, the course work included three assignments that counted for $60 \%$ of the final grade, in addition to final examination for $40 \%$.

After two lectures about different methods for the estimation of space cooling/heating loads and energy demand (e.g., bin, CLTD, heat balance), students were exposed to the Radiant Time Series (RTS) method. This newer method is suitable for the estimation of peak cooling load for design purposes. In addition, it gives a quick estimation of how the conductive heat gains, for instance through walls, are separated into the convective component of the space cooling load, and the radiative component that takes into account the thermal storage and later release. For the assignment no.1, students wrote the code in Matlab or Excel for the RTS method.

Students received the following information:

1. The room has only one exterior wall facing South of 4 $\mathrm{m} \times 4 \mathrm{~m}$, without windows.

2. The outdoor air infiltration and internal gains from people, lights, and equipment are neglected.

3. Thermostat set point is $22.0^{\circ} \mathrm{C}$. Inside surface temperature of partitions, floor, ceiling, and furniture is also $22.0^{\circ} \mathrm{C}$.

4. Outside surface of exterior wall: $\mathrm{h}_{\mathrm{o}}=17 \mathrm{~W} / \mathrm{m} 2 ; \alpha=$ 0.87 .

5. Inside surface of exterior wall: $\mathrm{h}_{\text {convection }}=4 \mathrm{~W} / \mathrm{m}^{2}$; $\mathrm{h}_{\text {radiation }}=3 \mathrm{~W} / \mathrm{m}^{2}$

7. Weather data for summer design day.

8. Conduction Time Factors (Table 16, ASHRAE, 2017) and Radiant Time Series (Table 19, ASHRAE, 2017).
They applied the RTS method for the estimation of the space cooling load of this room over 24 hours, and compared the results obtained from two different walls (ASHRAE wall \#1 and wall \#2) (Figure 1).

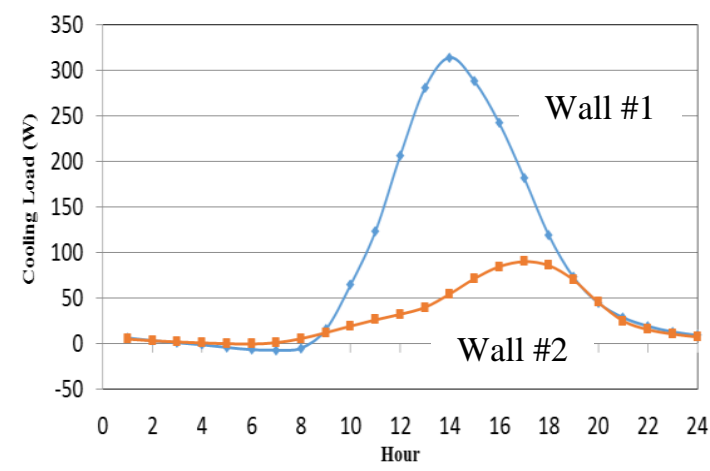

Figure 1: Comparison of hourly cooling load of a room due to two ASHRAE wall types.

The goal of the assignment no.2 was the estimation of annual energy performance of a school building that complies with the National Energy Code of Canada for Buildings (NECB, 2015) and Regulation respecting energy conservation in new building (Quebec, 2018). ANSI/ASHRAE/IES Standard 90.1 (2016) was used for additional requirements, when needed.

The assignment no.3 was a continuation of the second assignment with the goal of estimation of changes of the energy performance of base case model (assignment no.2) due to energy conservation measures (ECMs).

The class population was composed of 19 undergraduate students in the fourth year of the Building Engineering program, and 18 graduate students with different first degrees (e.g., mechanical, civil, architecture) registered for M.A.Sc (thesis option), M.Eng (courses option) and $\mathrm{Ph} . \mathrm{D}$. programs.

To compensate for the difference of one credit compared with the U/G course, the graduate students completed additional work. In the assignment no.2, they calculated the life cycle cost of energy use for the building operation, using the economic indicators from Bank of Canada and Hydro Quebec, and building economic duration of 30 years. In the assignment no.3, they estimated the impact of changes of the building envelope on the environmental impact, expressed by Global Warming Potential index in ton-eqCO $\mathrm{CO}_{2}$, using the Athena Impact Estimator software (Athena, 2018).

\section{Assignment no.2}

The assignment had the following teaching objectives:

1. Exploration, learning and application of the requirements of National Energy Code of Canada for Buildings (NECB, 2015), and Regulation respecting energy conservation in new building (Quebec, 2018), for the preliminary design of a school building and HVAC system.

2. Drawing of the schematic flowchart of the HVAC system, and explanation of the system operation. Selection of design and operation variables in compliance with the codes/standards. 
3. Understanding, learning and usage of a detailed building energy analysis program (eQuest, 2018) for the estimation of energy performance of a school building with a complex HVAC system.

4. Understanding of relationship between the: (i) space cooling/heating loads, (ii) secondary HVAC system cooling/system loads, and (iii) primary equipment energy use.

5. Estimation of the whole building energy performance, along with the indices of performance of HVAC equipment.

6. Learning from mistakes and errors in the input data and HVAC system description.

7. Raising students' confidence in their ability to estimate the energy performance of a building by using a detailed energy analysis program (eQuest).

The case study school building in Montreal has the footprint $40 \mathrm{~m} \times 70 \mathrm{~m}$ with five floors above ground, with the large facade facing south (Figure 2). The complexity of the building follows the complexity of reference building as defined in NECB (2015).

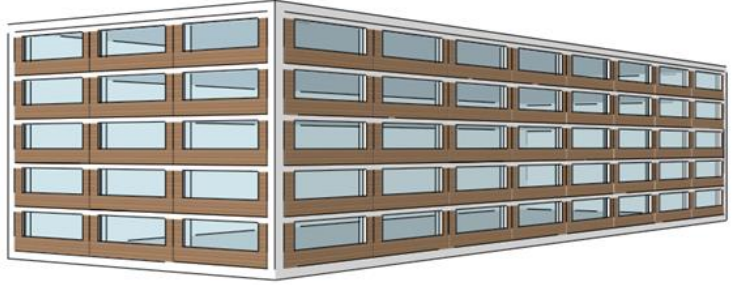

Figure 2: Sketch of the school building model.

The basement was not included in the assignment. Electricity is the only source of energy. The HVAC system complies with the prescriptive requirements and performance path method of NECB (2015). Sanitary hot water, elevators, ventilation hoods, exterior lighting, and any other equipment were not included in the assignment. The development of the eQuest input file for such a building with complex HVAC system, which must comply with many requirements from the prescriptive and/or performance paths, was not a straightforward application for students. They needed to understand well the structure and language of such codes/standards, the explanation of inputs to eQuest, have a good understanding of the HVAC system, and of design and operation variables. Students realized quickly that there was an abrupt step in the learning curve from their experience with the assignments of previous HVAC design courses.

Figure 3 presents the monthly end-use electric demand of the school building as an example of results obtained by one student, as displayed by the eQuest program in the summary output.

The detailed output text file (.SIM) contains the complete list of inputs, parameters calculated from the inputs, and outputs. The file can reach 200 pages or more depending of the complexity of building model. The detailed results from simulations, discussed in the paper, are extracted from this detailed text file.

\section{Electric Demand (kW)}

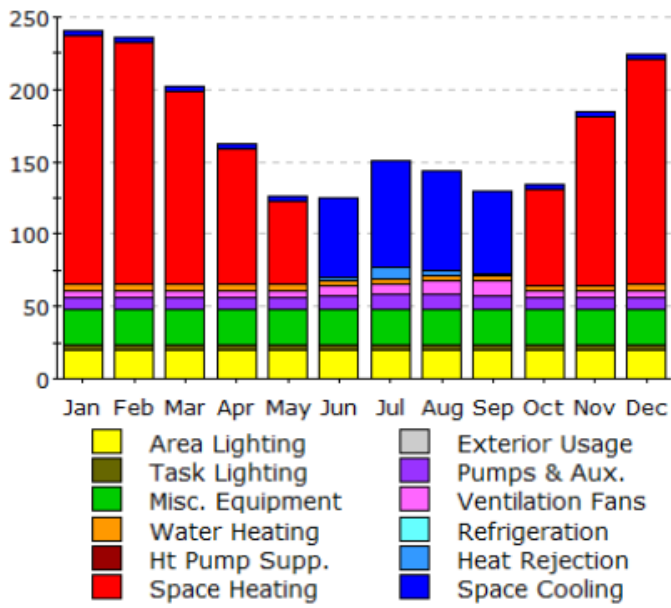

Figure 3: Example of monthly end-use electric demand of the school building from eQuest program.

To verify the simulation results, students were asked to review the simulation input and output files. They looked for errors, and compared the simulation results with the codes/standards prescriptions and design indices. If required, they needed to execute a few iterations to reach that compliance with the codes. They compared the predicted annual energy consumption with data from existing buildings of similar type and climate, energy price, codes and operation context.

Each student was asked to submit a report of no more than 12 pages including a table of design data according to codes/standards; schematic diagram of HVAC system; analysis of results; conclusions; and references. The author requested from each student the input file (.INP) and simulation output file (.SIM) for verification.

\section{Results of assignment no.2 and discussion}

The author compiled two classes of results from the simulation output files:

1. Indicators that are usually reported for the assessment of annual whole building energy performance, and for the model calibration:

(i) Monthly and annual site energy use, in $\mathrm{kWh} /\left(\mathrm{m}^{2} \cdot \mathrm{yr}\right)$ (from BEPU report),

(ii) Monthly and annual energy cost, in $\$ /\left(\mathrm{m}^{2} \cdot \mathrm{yr}\right)$ (from ES-E report),

(iii) Monthly and annual peak electric demand, in $\mathrm{W} / \mathrm{m}^{2}$ (from PS-E report), and

(iv) Monthly and annual electric load factor (ELF).

2. Indicators that provide additional information about the model performance, directly extracted or calculated from the eQuest outputs. However, students do not frequently extract these results from the eQuest simulation file for further analysis. Some indicators used in this assignment are as follows: 
(i) Total space cooling and heating loads (from LS-D report);

(ii) Total HVAC system cooling and heating loads (from SS-D report);

(iii) Total electric system load (from SS-D report);

(iv) U-value of walls, windows and overall U-value of envelope (from LV-E report);

(v) Design supply fan flow rate, in $\mathrm{L} / \mathrm{s} / \mathrm{m}^{2}$, and fan power demand, in W/L/s (from $\mathrm{SV}$-A report);

(vi) Specific cooling capacity, in $\mathrm{m}^{2}$ floor area/kW of cooling (from SS-D),

(vii) Power demand of pumps for chilled and condenser water, in W/kW of cooling (from PV-A and SS-D reports), and

(viii) Contribution of major end-uses (lights, appliances, cooling, heating, fans and pumps) on the annual energy use (from PS-B report).

The compilation of results from all students required first the verification of data quality.

(i) Three students used wrong input data for walls, which led to U-value of 3.25 or $13.05 \mathrm{~W} /\left(\mathrm{m}^{2} \cdot \mathrm{K}\right)$ compared to the NECB (2015) value of $0.247 \mathrm{~W} /\left(\mathrm{m}^{2} \cdot \mathrm{K}\right)$ prescribed for Montreal that is in zone 6 with 4300 Celsius heating degree-days;

(ii) Two students misinterpreted the NECB (2015) description of the reference system no.6 that is recommended for schools. They selected the multi-zone system option in eQuest when they should have selected the variable volume (VAV) system option. The author noticed that a few students have not recognized the jargon used in tool interfaces.

(iii) In a few cases, the structure of electricity rate of Hydro Quebec was not correctly input, which led to annual energy cost of about $75 \$ /\left(\mathrm{m}^{2} \cdot \mathrm{yr}\right)$ compared with the average of about $20 \$ /\left(\mathrm{m}^{2} \cdot \mathrm{yr}\right)$ obtained by all other students.

The author presumed, upon the detailed analysis of all input and output files, that not all students had the patience to perform all iterations as suggested for improving the quality of simulations. As a result, some errors noticed in the final submission might explain the variation of results among students.

The summary of main results from the eQuest simulations, extracted from the .SIM reports of all 37 students, are presented in Table 2, and compared with the corresponding benchmarks.

Additional comments:

1. The predictions of whole building energy use were reasonable since the sanitary hot water, elevators, ventilation hoods, exterior lighting, and any other laboratory equipment are not included in the building model.

2. Figure 4 shows the predicted trend of the annual energy cost versus annual energy consumption.
Table 2: Summary of main results from all 37 students.

\begin{tabular}{|c|c|c|}
\hline $\begin{array}{l}\text { Predicted index of } \\
\text { performance }\end{array}$ & $\begin{array}{l}\text { Mean } \pm \text { standard } \\
\text { deviation }\end{array}$ & Benchmark \\
\hline $\begin{array}{c}\text { Whole building annual } \\
\text { energy use } \\
{\left[\mathrm{kWh} /\left(\mathrm{m}^{2} \cdot \mathrm{yr}\right)\right]}\end{array}$ & $150.00 \pm 55.2$ & $\begin{array}{l}275 \text { (Issa et } \\
\text { al., 2011) }\end{array}$ \\
\hline $\begin{array}{l}\text { Whole building annual } \\
\text { electricity cost } \\
{\left[\$ /\left(\mathrm{m}^{2} \cdot \mathrm{yr}\right)\right]}\end{array}$ & $20.5 \pm 11.5$ & \\
\hline $\begin{array}{l}\text { U-value of windows } \\
{\left[\mathrm{W} /\left(\mathrm{m}^{2} \cdot \mathrm{K}\right)\right]}\end{array}$ & $2.53 \pm 0.65$ & $\begin{array}{c}<2.2 \\
(\mathrm{NECB}, \\
2015)\end{array}$ \\
\hline $\begin{array}{l}\text { U-value of exterior } \\
\text { walls }\left[\mathrm{W} /\left(\mathrm{m}^{2} \cdot \mathrm{K}\right)\right]\end{array}$ & $0.24 \pm 0.06$ & $\begin{array}{c}<0.24 \\
(\mathrm{NECB}, \\
2015)\end{array}$ \\
\hline $\begin{array}{l}\text { Total supply airflow } \\
\text { rate }\left[\mathrm{L} /\left(\mathrm{s} \cdot \mathrm{m}^{2}\right)\right]\end{array}$ & $4.85 \pm 1.17$ & $<3.8-5.0$ \\
\hline $\begin{array}{c}\text { Power demand for } \\
\text { motors of combined } \\
\text { supply and return VAV } \\
\text { fans [W/(L/s of supply } \\
\text { air)] }\end{array}$ & $1.92 \pm 0.23$ & $\begin{array}{l}<2.65 \\
\text { NECB } \\
(2015)\end{array}$ \\
\hline $\begin{array}{l}\text { Specific chiller capacity } \\
{\left[\mathrm{m}^{2} / \mathrm{kW}\right]}\end{array}$ & $12.27 \pm 3.0$ & $>9.3-11.9$ \\
\hline $\begin{array}{l}\text { Power demand for } \\
\text { motors of all the pumps } \\
\text { in the hydronic system } \\
\text { [W/kW of cooling load] }\end{array}$ & $15.77 \pm 2.84$ & $\begin{array}{c}<14 \\
{[\mathrm{NECB}-} \\
2105]\end{array}$ \\
\hline $\begin{array}{l}\text { Power demand for } \\
\text { pumps of condenser } \\
\text { water loop [W/kW] }\end{array}$ & $22.80 \pm 5.04$ & $\begin{array}{c}<12 \\
(\mathrm{NECB}, \\
2015) .\end{array}$ \\
\hline
\end{tabular}

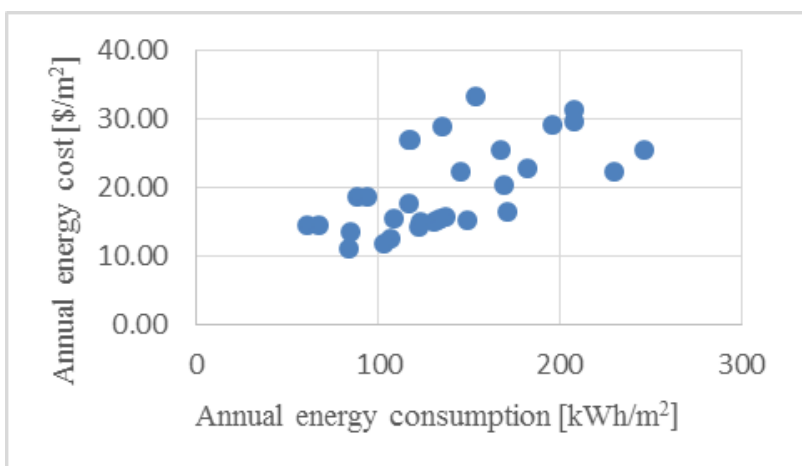

Figure 4: Annual energy cost versus annual energy consumption.

3. Total predicted supply airflow rate was higher than the recommended range of 4.03-9.58 L/(s. m2) (ASHRAE 1987). However, the predictions are in agreement with the current practice of about $3.8-5 \mathrm{~L} /(\mathrm{s} \cdot \mathrm{m} 2)$ for new buildings with improved lighting systems and heat recovery from exhaust air.

4. Predicted specific chiller capacity was much higher than the recommended range of 3.97-6.34 m2/kW (ASHRAE 1987). However, the predictions are closer to 
the current practice of about $9.3-11.9 \mathrm{~m} 2 / \mathrm{kW}$ in the case of new buildings.

5. Most predictions of the combined power demand, required by the motors of all the pumps in the hydronic system, exceeded the maximum allowed by NECB (2015).

6. All predictions of the power input to pumps of condenser water loop exceeded the maximum allowed by NECB (2015).

7. NECB (2015) prescribes the minimum performance of HVAC equipment. For instance, the minimum COP of a packaged water centrifugal chiller, water-cooled is given in terms of the chiller capacity in $\mathrm{kW}$. In most cases, students used either the eQuest default value of COP, or the minimum value of $\mathrm{COP}=3.98$ from Quebec (2018). They should have selected the value of COP in terms of cooling capacity (e.g., $\mathrm{COP}=5.236$ ).

The author compiled and presented in the classroom the results of all students, and discussed the errors and misunderstandings noticed in the reports and input files.

In this assignment, all students used a building of given dimensions, and physical properties and VAV system in compliance with building energy-related codes. However, the estimations of annual whole building energy use were scattered around the average value obtained by 37 students, with the Coefficient of Variance of the Root Mean Square Error (CV-RMSE) of 39\%. For the annual energy cost the CV-RMSE was $56 \%$.

The average value of different indicators was almost equal from U/G and graduate students, with a larger dispersion of results from graduate students.

The author concluded that the predictions of annual whole building energy use and cost should not be the only outputs of interest. The assessment of simulation quality should include other indices of performance at the system or equipment level. Those indices should be compared with code/standard requirements or design specifications.

The model calibration of an existing building with many unknown or uncertain values of design and operation variables is challenging. Hence, the variation of predictions made by several users for an existing building would be even larger than of the results presented in this paper.

\section{Assignment no.3}

Students investigated the impact of two separate ECMs applied to the base case building (assignment no.2):

ECM\#1 uses the daylighting control, and two different values of the window-to wall ratio: (a) $W W R=0$ and (b) $\mathrm{WWR}=1$; the base case model $\mathrm{WWR}=0.4$; and

ECM\#2 uses the natural gas as the energy source for heating needs, and electricity for all other energy needs.

For each ECM, students predicted the change of annual whole building energy use, annual peak electric demand, annual energy cost, and annual Electric Load Factor.

\section{Results of assignment no.3 and discussion}

The decrease of annual whole building energy use and cost due to the energy conservation measure ECM\#1(a), ECM\#1(b), and ECM\#2 is presented in Table 3.

Table 3: Decrease of the whole building energy use and cost due to ECMs.

\begin{tabular}{|c|c|c|c|}
\hline & $\begin{array}{c}\text { ECM\#1(a) } \\
\text { WWR=0 }\end{array}$ & $\begin{array}{c}\text { ECM\#1(b) } \\
\text { WWR=1 }\end{array}$ & $\begin{array}{c}\text { ECM\#2 } \\
\text { Natural gas } \\
\text { for heating }\end{array}$ \\
\hline $\begin{array}{c}\text { Annual } \\
\text { building } \\
\text { energy use } \\
{[\%]}\end{array}$ & $10.7 \pm 11.4$ & $-(11 \pm 18.4)$ & $-(12 \pm 33)$ \\
\hline $\begin{array}{c}\text { Annual } \\
\text { energy cost } \\
{[\%]}\end{array}$ & $14.5 \pm 8.0$ & $-(9.8 \pm 16.2)$ & $33.1 \pm 13.7$ \\
\hline
\end{tabular}

In the case of changes to the building envelope, the change of annual energy cost followed the trend of change of annual energy use.

In the case of changing the energy source for heating from electricity to natural gas (ECM\#2), the annual energy use increased because of lower thermal efficiency of boiler of 0.83 (NCEB, 2015) compared with electric heating, and the additional power input to pumps of the hot water loop. However the annual energy cost decreased because of lower price of natural gas $(\$ 3.55 / \mathrm{GJ}$ or $\$ 0.0128 / \mathrm{kWh})$ compared with about $\$ 0.07 / \mathrm{kWh}$ of electricity (including the price of energy use and peak demand).

The large variation of students' predictions of annual energy use for ECM\#2 was due two causes:

(i) Some students selected the natural-gas boiler thermal efficiency of 0.8 (default value in eQuest) instead of 0.83 (NECB, 2015).

(ii) Some students connected the natural gas-fired boiler only with the heating coil of AHU, or only to the heating coil and the reheating coils of VAV boxes. When the baseboard heaters were not connected to the hot water loop, they received warnings of insufficient heating capacity in zones. They simply disregarded those warnings.

\section{Conclusion}

The scope of work requested from students registered in these two courses was much larger than the scope of other core or elective courses that they completed in previous terms. Those courses focused on: (i) the fundamental concepts and methods of assessment of energy flows in buildings, and (ii) the key elements of design of HVAC systems.

The author asked students to apply the codes requirements for the preliminary design of a school building and a complex VAV system, and to estimate the energy-related performance at the building, system and equipment level, by using eQuest, a detailed energy analysis program.

The learning curve was abrupt. The author' comparison of all students' results proved that the annual whole 
building energy use and cost should not be the only results of interest from such a detailed simulation. If only the whole building energy performance is analysed, many weaknesses and errors are not discovered. Other results directly extracted or calculated from the output file should be compared with codes requirements, indices from reference publications, and indices derived by consulting firms from their practice.

The author considers that the time available for the completion of assignments no. 2 and no. 3 was sufficient for achieving the teaching objectives. The program used in these assignments, eQuest, is free of charge and most students installed on their own laptops. In addition, the program was installed in the computer laboratories of the faculty.

Each student developed his/her own building model with eQuest; this was an individual not a group assignment. The diversity of values selected by students for inputs (as observed by the author in all students' input files), and the differences of results led the author to the conclusion that they really submitted an individual work, although it is possible that in the computer laboratory they communicated and explored together the issues faced during the development of eQuest file.

The complexity of prescriptions and performance path model (NECB-2015) made impractical the development of the "true eQuest model," as students are not limited to one single value for some inputs. For instance, students are allowed to select any reasonable value of thermal resistance of exterior wall that is greater than the minimum required by eQuest, or a chiller with greater COP than the minimum required by NECB (2015).

In the case of assignments no. 2 and no.3, the building dimensions were given to students, and the physical properties and HVAC system details were supposed to comply with the code. Even though the conditions were controlled, the results from all students presented a large dispersion due to errors and misinterpretations.

One can expect that in the case of modeling of an existing building, with many unknown or uncertain values of design and operation variables, the variation of predictions made by several users would be even larger than of the results presented in this paper.

\section{Acknowledgement}

The author acknowledge the work of students registered in these two courses who have contributed with their results to this paper.

\section{References}

ASHRAE (2017). Handbook: Fundamentals. Chapter 18. Atlanta, GA.

ANSI/ASHRAE/IES (2016). Standard 90.1- Energy Standard for Buildings Except Low-Rise Residential Buildings. Atlanta, GA.

ASHRAE (2004). Standard 140-2004, Standard Method of Test for the Evaluation of Building Energy. Atlanta, GA.
ASHRAE (1987). ASHRAE Pocket Handbook for Air Conditioning, Heating, Ventilation and Refrigeration. Atlanta, GA.

Athena (2018). Athena Impact Estimator version 5.2. Athena Sustainable Materials Institute. http://www.athenasmi.org/news-item/impactestimator-for-buildings-version-5-2-build-01-pressrelease/. Last access: December 15, 2018.

Beausoleil-Morrison, I. and Hopfe, C.J. (2015). Teaching Building Performance Simulation through a Continuous Learning Cycle. Proceedings from BS2015. Hyderabad (India), December.

Beausoleil-Morrison, I. (2018). Learning the fundamentals of building performance simulation through an experiential teaching approach. Journal of Building Performance Simulation, DOI: 10.1080/19401493.2018.1479773.

Bernier, M., Kummert, M., Sansregret, S., Bourgeois, D. and Thevenard, D. (2016). Teaching a building simulation course at the graduate level. Proceedings from eSim conference. Hamilton, ON (Canada). May.

Charles P. R., Thomas, C. R. (2009). Building performance simulation in undergraduate multidisciplinary education: Learning from an architecture and engineering collaboration. Proceedings from BS2009. Glasgow (UK), July.

Equa Simulation AB. (2016). User Manual, IDA Indoor Climate and Energy,Version 4.7, January 2016, http://equa.se/en/ida-ice.

eQUEST (2018). The QUick Energy Simulation Tool 3.65. http://www.doe2.com/equest/. Last access: December 15, 2018.

Hopfe, C.J., Soebarto, V., Crawley, D. and Rawal, R. (2017). Understanding the differences of integrating building performance simulation in the architectural education system. Proceedings from BS2017. San Francisco (USA), July.

Kumaraswamy, S.B. and de Wilde, P. (2015). Simulation in Education: Application in Architectural Technology Design Projects. Proceedings from BS2015. Hyderabad (India), December.

NEBC (2015). National Energy Code of Canada for Buildings. National Research Council. Ottawa, ON.

Ouf, M.M., \&d Issa, M.H. (2017). Energy consumption analysis of school buildings in Manitoba, Canada. International Journal of Sustainable Built Environment 6(2), 359-371.

Rabenseifer, R. (2015). Teaching Building Performance Simulation Using Generic Simulation model. Proceedings from BS2015. Hyderabad (India), December.

Reinhart, C.F., Dogan, T., Ibarra, D. and Wasilowski Samuelson, H. (2011). Learning by Playing Teaching Energy Simulations as a Game. Proceedings from BS2011. Sydney (Australia), November. 
Reinhart, C.F., Dogan, T., Ibarra, D. and Wasilowski Samuelson, H. (2012). Learning by Playing Teaching Energy Simulations as a Game. (2012) Journal of Building Performance Simulation 5(6): 359-368.

Quebec (2018). Regulation respecting energy conservation in new buildings. E-1.1., r. Editeur official, Quebec.

Schmid, A.L. (2008). The introduction of building simulation into an architectural faculty: preliminary findings. Journal of Building Performance Simulation, 1:3, 197-208.

Strobe, T., Verstraeten, R., Delgust, M., Laverge, J., De Meyer, R. and Janssens, A. (2015). Using a Building Information modelling Approach for Teachimh about Residential Energy Use and Official Energy Performance. Proceedings from BS2015. Hyderabad (India), December.

Zweifel, G. (2017). Teaching Building Simulation to HVAC Engineering Bachelor Students. Proceedings from BS2017. San Francisco (USA), USA, July. 